\title{
Introducing The Representational Measurement Project In Accounting
}

\author{
Saratiel Weszerai Musvoto, North West University - Vaal Triangle Campus, South Africa
}

\begin{abstract}
This study introduces a representational measurement (a theory that establishes measurement in the social sciences) perspective to the accounting concept of measurement. Accounting studies have long sought to establish foundations (theory) of measurement in accounting without success. This is because the accounting concept of measurement is based on the axioms of quantity which ultimately result in the classical theory of measurement and are not suitable for social science disciplines such as accounting, but rather for the natural sciences. The measurement of attributes of social science phenomena does not give rise to a natural concatenation operation, which is pivotal to invoking a theoretical concept of an absolute continuous quantity that forms the basis of the classical theory of measurement. As a result, this study suggests criteria whose development might eventually lead to the construction of representational measurements in accounting.
\end{abstract}

Keywords: classical theory of measurement; representational measurement; concatenation; Mitroff model

\section{INTRODUCTION}

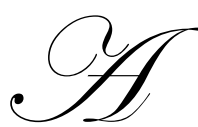

ccounting is regarded as a measurement discipline (IASB, 2009; Wolk et al. 2002). However, research has not, for over seventy years, succeeded in establishing foundations of accounting measurement. According to authors such as Musvoto (2010), McLean (2006), Ryan et al. (2002), Walker and Jones (2003), Chambers (1997), Stamp (1981) and Tinker (1985), there is consensus that a theory of measurement is lacking in the accounting discipline. In addition, they point out that there are no reasons cited for the lack of a theory of measurement in accounting. This makes clear the absence of a theory of measurement in accounting.

According to Ryan et al. (2002), every process of measurement must have an underlying theory of measurement. This suggests that it is inappropriate to refer to accounting as a measurement discipline in the absence of a theory of measurement. Furthermore, if the reason for the lack of a theory of measurement in accounting is unknown, then it is not possible to solve the measurement problem in accounting. Therefore a description of the measurement problem in the accounting concept of measurement is needed - It is necessary to understand the problem first before a solution can be suggested.

Given the discussion above, the purpose of this study is to describe the reality of the problem situation in accounting measurement, to develop a conceptual model for the accounting measurement concept, and then to discuss part of the formulation of a scientific model to address the problem. This study also provides a precise definition of the nature of the numerical assignments in the accounting discipline. However, it is important to note that this study is exploratory in nature.

The study commences with a discussion of the systems view of solving the measurement problem in accounting in Section 2. This is followed by the development of the conceptual model of the reality problem in Section 3 and its subsections, followed by a proposed scientific model of a solution to the measurement problem in accounting in Section 4. Section 5 gives the conclusions. 


\section{A SYSTEMS VIEW OF SOLVING THE MEASUREMENT PROBLEM IN ACCOUNTING}

In Section 1 it was pointed out that among other things the purpose of this study is to describe the reality of the problem situation in accounting measurement to allow the development of a conceptual model for the accounting concept of measurement. In order to achieve this goal, this study employs the model for problem solving designed by Mitroff et al. (1974:48). It involves a systems view of problem solving. According to Mitroff et al. (1974), a systems approach to problem solving includes conceptualisation, modelling, model solving and implementation. The scope of this study may be explained more specifically in terms of the model for problem solving designed by Mitroff et al. (1974), which is depicted in Figure 2.1.

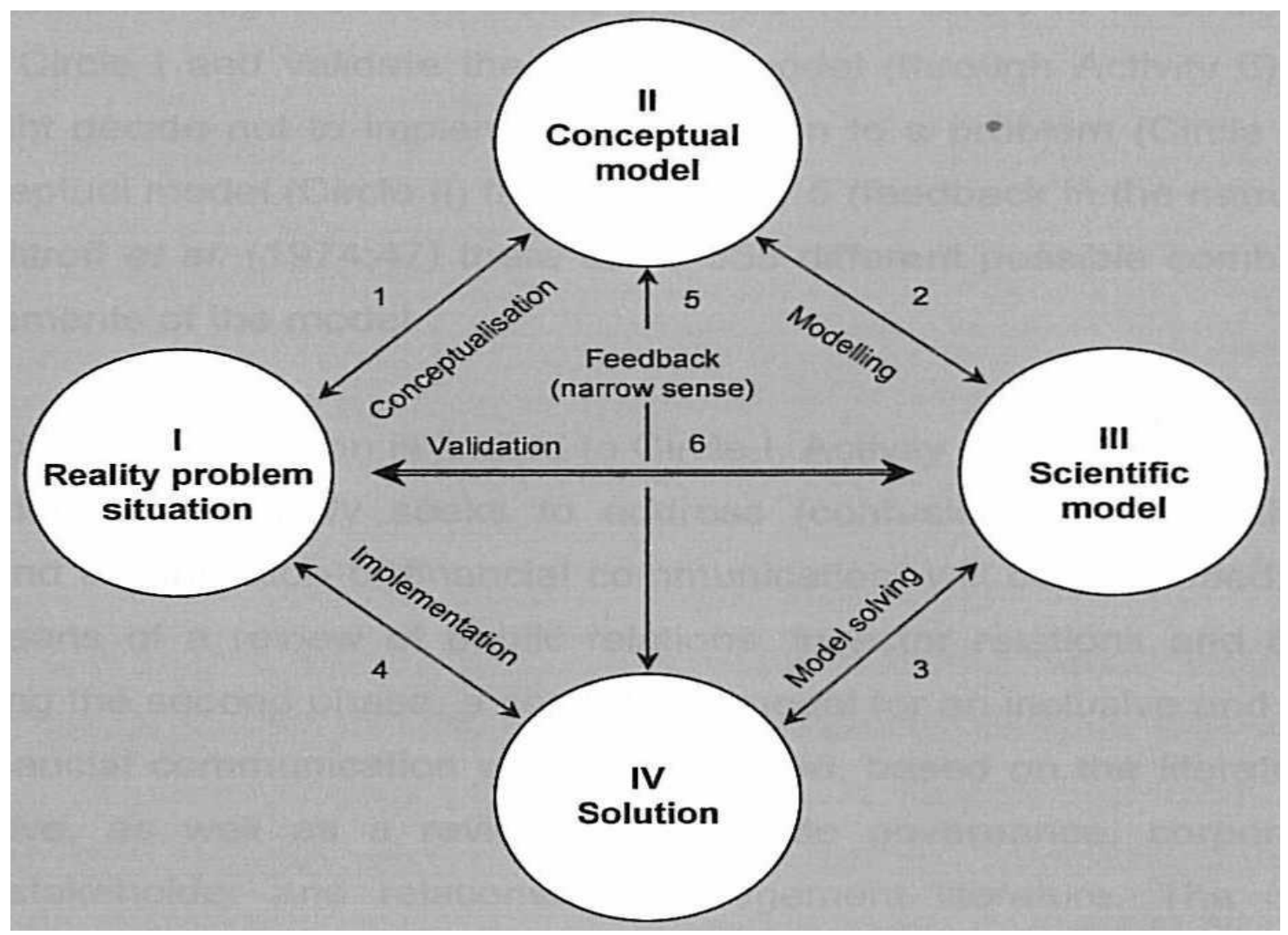

Figure 2.1 A Systems View Of Problem Solving Source: mitroff et al. (1974:48)

The model takes a holistic or systems view of different varieties of scientific activities. It has no definite beginning or end. In terms of this model, research is seen as continuous. A research project could begin at any of the circles $1,2,3$ or 4 . In relation to this study, the establishment of the reasons that the accounting measurement concept does not have a theory of measurement could begin at any point of the model. For example, a research project may start at circle 1 with the identification of a problem situation. In Section 1 it was noted that the problem in this study is that there is no clear reason why a theory of accounting measurement is absent and why an appropriate solution has not been proposed. This suggests that this study could begin with activities that are aimed at discovering the reasons for the absence of a theory of measurement. Activity 1 conceptualises the problem to allow the development of a conceptual model as in circle 2. In this study it would be necessary to conceptualise the measurement problem in accounting before a conceptual model can be developed. According to Mitroff et al. (1974), the conceptual model defines in broad terms the particular problem to be solved. It then specifies the field variables that will be used to define the nature of the problem and the level at which the variables will be treated. In 
this study this would entail the specification of the variables that affect the accounting concept of measurement. Currently these variables are not known.

Activity 2 entails the formulation of the scientific model in circle 3. According to Rivett (1972:9), a scientific model is a set of either qualitative or quantitative logical relationships which link the relevant features of the reality with which we are concerned. This would require the specification of a scientific model of the measurement problem in accounting, which would in turn require the identification of all the variables that affect accounting measurement and the relationships between them. A model of the variables that affect accounting measurement that is empirically testable would qualify as a specified scientific model.

The third phase would be to carry out activity 3 to derive a solution from the scientific model, and activity 4 would entail feedback from the solution to the original problem situation. In validation activity 6 , the degree of correspondence between reality and the scientific model is evaluated. Finally, in activity 5, namely feedback in the narrow sense, problem-solving activities (circles 2,3,4) are applied, with the goal of deriving better scientific solutions from the activities and elements in the model. Mitroff et al. (1974:53) remark that a single research project rarely covers all the circles and activities. Various combinations of circles and activities can be used. In this study this would entail deriving a solution to the measurement problem in accounting, and would involve the creation of a theory of accounting measurement and the specification of the foundations of accounting measurement. The theory of accounting measurement thus created would then be tested, followed by the evaluation of the feedback on the validity of the theory.

The research for this study is limited to circle 1 , activity 1 , circle 2 and partly activity 2 . In the first phase, the problem which this study seeks to address is discussed.

\section{THE REALITY PROBLEM SITUATION IN ACCOUNTING MEASUREMENT AND THE DEVELOPMENT OF A CONCEPTUAL MODEL}

In this section, Mitroff's (1974) 4-phase model for problem solving is used to contexualise and develop a conceptual model of the problems within the accounting concept of measurement. The Mitroff model described in Section 2, prescribes four phases of development. As this study is exploratory in nature, phase 3 and phase 4 of the Mitroff model will not be used, and will be limited to phases 1 and 2. A scientific model of accounting measurement is also proposed. That is, part of phase 3 of Mitroff's model is discussed.

\subsection{Phase 1 Of Mitroff's 4-Phase Problem-Solving Model}

This phase stipulates the identification of a reality problem situation. In this study, the problem situation is contextualised through a literature review and the existing accounting concept of measurement is analysed.

\subsubsection{Literature Review}

Recommendations for solutions to the measurement problem in accounting abound in the accounting literature. For over 40 years accounting researchers have proposed solutions to the measurement problem, but have not succeeded in solving it. For example, Vickrey (1970), states that there is no property that is currently measured in accounting apart from monetary units. Furthermore, Vickrey (1970) holds the view that accounting can only become a measurement discipline if an extensive property is found and also if the nominal scale is excluded. This does not specify the grounds on which the epistemological position is based. For example, there is no support for the reason why it is necessary for the accounting measurement concept to have an extensive property in order for accounting to be a measurement discipline. In the first place, there are no grounds given for eliminating approaches to solving the measurement problem other than finding an extensive property and excluding nominal scales from the accounting concept of measurement. It is necessary to justify in a philosophical manner why only attributes that give rise to different measurements of the same attribute that are structurally identical should establish measurement in accounting. It is also necessary to note that axiom systems, other than extensive systems, such as difference measurement, conjoint measurement, and expected utility measurement (Luce et al., 1971:124) have been developed in the social sciences as a basis for fundamental measurement. Therefore it is also necessary to justify why 
accounting as a social science is an exception. Furthermore, authors such as Ijiri (1975), Orbach (1978), Staubus (1985), Willet (1987, 1988) and Walker and Jones (2003) also highlight the absence of foundations of measurement in accounting. They all attempted to prescribe certain measurement solutions to the accounting concept of measurement without first identifying the problem. In particular, Ijiri (1965) holds the view that value allocation rule as a theory of measurement can stand in for the absent accounting measurement theory. This author did not explain how accounting could be a measurement discipline without a theory of measurement. In addition, there are no reasons given to support the viewpoint that the value allocation rule will be sufficient to solve an unknown accounting measurement problem. Moreover, Ijiri (1975) prescribes a theory-based measure theory as a substitute for a theory of measurement. It is important to note that measure theory does not require the specification of the attribute to be measured, while measurement theory does (Musvoto, 2008). Again, no reasons are cited for proposing such a solution to the measurement problem in accounting. Authors such as Orbach (1978), Staubus (1985), Willet $(1987,1988)$ and Walker and Jones (2003) also put forward various solutions to the measurement problem in accounting without first specifying the problem. It is important to note that if something is not available, this does not in itself justify the prescription of something else in its place. In order to solve a problem it is necessary to define the problem first and then find solutions.

\subsubsection{Analysing The Accounting Concept Of Measurement}

The IASB (2009), in defining accounting measurement as "the process of determining the monetary amounts at which the elements of the financial statements are to be recognised and carried in the balance sheet and income statement," sets the tone for a theory of numerical assignments that does not require empirical verification. The most peculiar thing about this definition is also that it only defines measurement in terms of monetary units, the representing structure. No reference is made to exactly how or what they might represent. The IASB (2009) also points out that it is cost and value that are measured in accounting in order to recognise the elements of the financial statements. No empirical stipulation whatsoever is given in the accounting literature on how to identify cost or value. It follows that if the accounting theory of measurement is based on a perspective that is not subject to empirical verification, then it may be argued that the accounting discipline invokes a theoretical concept to explain monetary assignments, but it is a concept that itself is not open to direct verification. Given the viewpoint that the accounting discipline has not supplied ways of experimentally testing the hypothesis that monetary assignments meet the operational test of measurement, it may be argued that the account of measurement given in the accounting discipline is not intended to be an account of how measurement is attained in accounting practice. However, one may argue that the key theorem that is being advanced in the accounting literature is that for each ratio of accounting magnitudes there exists a positive real number; consequently this allows the measurability of an underlying continuous quantity (cost or value) in accounting using monetary units as an abstract structure. This viewpoint does not invoke measurement in the sense of how measurable empirical accounting structures can be defined using monetary units through observation and experiment. The failure to appreciate this fact has led to a frantic search for a theory of measurement based on empirical evidence in accounting for decades.

It is important to appreciate that modern measurement theory is concerned with how empirical relational structures can be defined through observation and experiment. As a result, modern principles of measurement in accounting cannot be defined upon a practice that is based on the classical theory of measurement. The methodology for finding a modern accounting theory of measurement has been based on the classical theory of measurement. For example, authors such as Vickrey (1970), Ijiri (1967, 1975), Orbach (1978), Willet (1988) and Walker and Jones (2003) prescribed solutions to the measurement problem in accounting that are based on the modern principles, but whose underlying objects of measurement are defined using the classical theory of measurement. For instance, they all use monetary units as the representing structure of value. According to Musvoto (2008), the measurement of monetary units requires the concatenation of monetary unit intervals, which requires empirical verification, while value has no defined empirical relational structure. This suggests that value is assumed to be a continuous quantity that is definable on the real line. Hence it can be deduced that the additive operation in value measurement is not intended to be a directly observable one. It is therefore inappropriate to assume that the empirical relational structure of value can be represented by monetary units. It is also clear from this that the modern principles of measurement have a tendency to identify both the meaning of the measure and the properties of empirical relational structure with the content of empirical intuition. It follows that accountants must therefore not try to modernise the accounting 
concept of measurement by interpreting this essentially theoretical concept of value as a more directly testable version.

It is not incorrect for accountants to regard continuity as a feature of the scientific concept of quantity. This viewpoint is derived from the natural sciences. According to Michell and Ernst (1996) Newton expressed it precisely when he pointed out that the ratio of one magnitude to another of the same kind (where the latter is understood as a unit) is expressed through an abstract (i.e. real positive) number. That is to say that the relation of a magnitude $a$ to $b$ is the same ratio as $c$ to $d$ when a measured by $b$ and gives the same number as $c$ measured by $d$. This is the viewpoint taken in the accounting discipline in the assignment of monetary units to the elements of the financial statements. In the accounting discipline, the monetary assignments made by different entities are taken, and at different epochs are taken to be of the same kind (IASB, 2009). If this is the case, the ratio of a monetary assignment in one epoch to another in a different epoch is considered to be of the same kind (where the latter is understood as a unit), and is therefore expressed through an abstract (real positive) number. As highlighted in this discussion, this viewpoint is correct if one regards value as a continuous quantity. However, if one takes the viewpoint that accounting is a social science (Flanders, 1961; Ryan et al., 2002), it may be argued that use of the classical theory of measurement in accounting is inappropriate. From the discussion in this section, it is important to note that adopting the classical measurement theory gives rise to extensive measurement. According to Luce et al. (1971), extensive measurement in the social sciences is not readily achievable due to the inadequate interpretation of the concatenation operation. Therefore, if this is the case it follows that a theory that includes other forms of measurement must be introduced into the accounting discipline.

\subsection{Phase 2 Of Mitroff's 4-Phase Problem-Solving Model}

The second phase of Mitroff's model (Mitroff et al., 1974) deals with the development of the conceptual model. This phase defines the problem to be solved in broad terms and specifies any variables that will be used to define the nature of the problem. The problems in the accounting concept of measurement have been discussed in Section 3.1 and its subsections. The problems identified in these sections concern mainly the areas of measurement discussed in the following sections.

\subsection{The Concept Of Representational Measurement}

In Section 3.1.2 it was noted that accounting is a social science. It was also argued that the classical theory of measurement is not suitable for the social sciences. This means that the only way accounting can be considered to be a measurement discipline is if accounting practices are compatible with the principles of the theory of measurement which establishes measurement in the social sciences. It can also be inferred that the field variables that are necessary in the development of the conceptual model of the problems in the accounting concept of measurement are determined by the requirements of this theory of measurement. According to Scott and Suppes (1958) measurement in the social sciences is established by the principles of the representational theory of measurement. If this is the case, it can be argued that the basis of the conceptual model of the measurement problem in accounting is founded on the process of the representational theory of measurement. Decoene et al. (1995:234) describe the process of representational measurement as follows:

One starts from an empirical relational structure, which consists of a set $X$ of objects (or events) characterised by a collection of descriptive events - relations Ri and possibly a collection of functional elements - operations oi defined with respect to these relations. The RTM concentrates on how to describe the empirical relational structure as succinctly and accurately as possible. This is done by formulating a set of qualitative axioms, which are an abstract description of what the empirical relational structure is. To study the possibility of measuring this empirical relational structure, RTM asks whether it can be represented by an abstract structure (in most cases Reals), given the set of qualitative axioms. To achieve this, RTM tries to prove both a representation and a uniqueness theorem. The representation theorem proves the existence of an order preserving mapping $f$ from the empirical relational structure into the abstract relational structure. The uniqueness theorem proves which transformations $f \quad$ f'are admissible. 
This extract indicates that the process of representational measurement has a specific starting point. It has to start with the identification of the object whose attributes are the subject of measurement. It is clear from this that a precise and clear description of the qualitative structure of the phenomenon to be measured is necessary before measurement can take place. The extract also shows that the identification of the object of measurement has to be followed by the identification of the attributes to be measured. Precise knowledge of the attributes to be measured is also required. It is evident from this that precise knowledge of the empirical relational structure of the phenomenon to be measured is necessary before measurement can take place. The extract also points out that the possibility of measurement is confirmed when an abstract structure that can be used to represent an empirical relational structure is found. That is to say, a search should be conducted to find a suitable numerical relational structure for representing the empirical relational structure. It is also clear from the extract that there are no set rules for choosing the numerical relational structure. The choice is entirely arbitrary. The extract also points out that after the abstract structure (numerical relational structure) is found it is necessary to specify the scales of measurement, in other words it is necessary to specify the relationship between the numerical relational structure and the empirical relational structure. This is because the relationship specifies how the numerical relational structure represents the properties of the empirical relational structure. The specification of a scale of measurement is equivalent to proving the representation and uniqueness theorems (Luce et al, 1971). This discussion highlights the procedures that create representational measurements. Anything short of this results in other representations, but not representational measurements. Therefore, if accounting is to be considered a measurement discipline, it has to adhere to these principles.

Figure 3.3.1 below is a flow chart which expresses the characteristics of the process of representational measurement. It helps to explain the kind of process that the accounting discipline needs to follow before it can be considered a measurement discipline. In Figure 3.3 some of the symbols used in the flow charts designed for this study are explained.

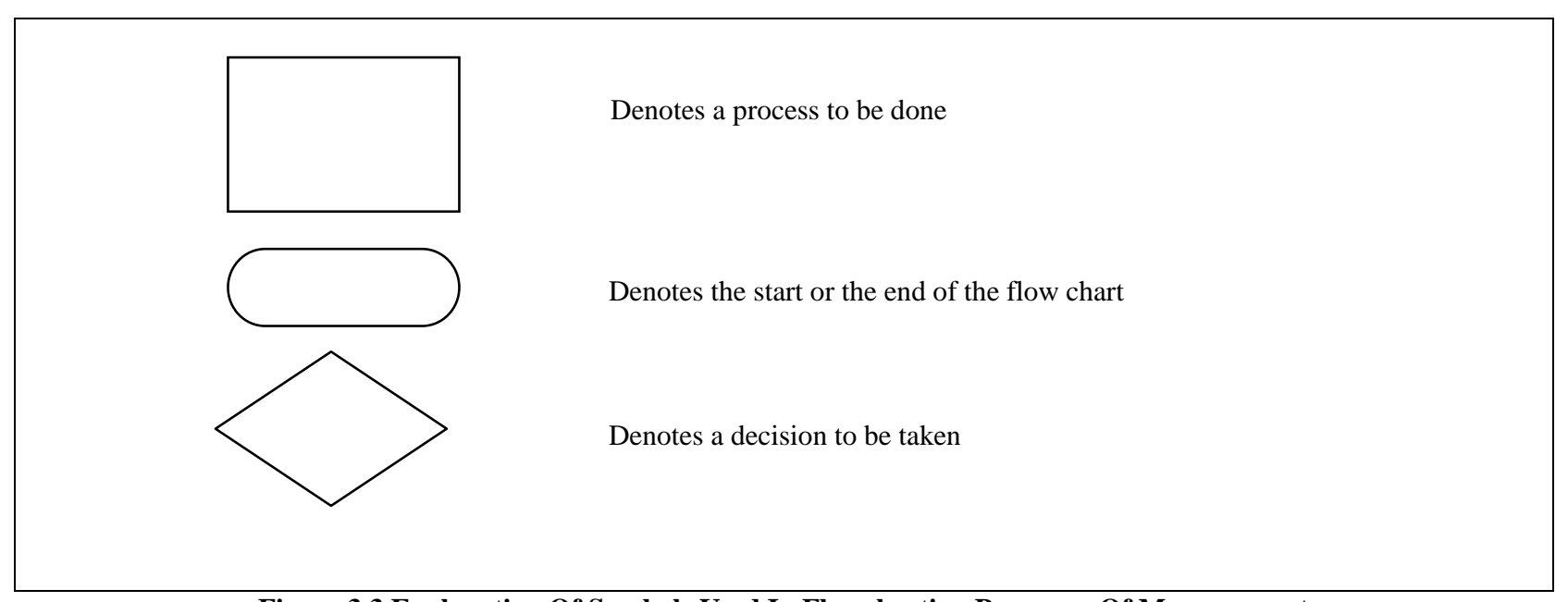

Figure 3.3 Explanation Of Symbols Used In Flowcharting Processes Of Measurement 


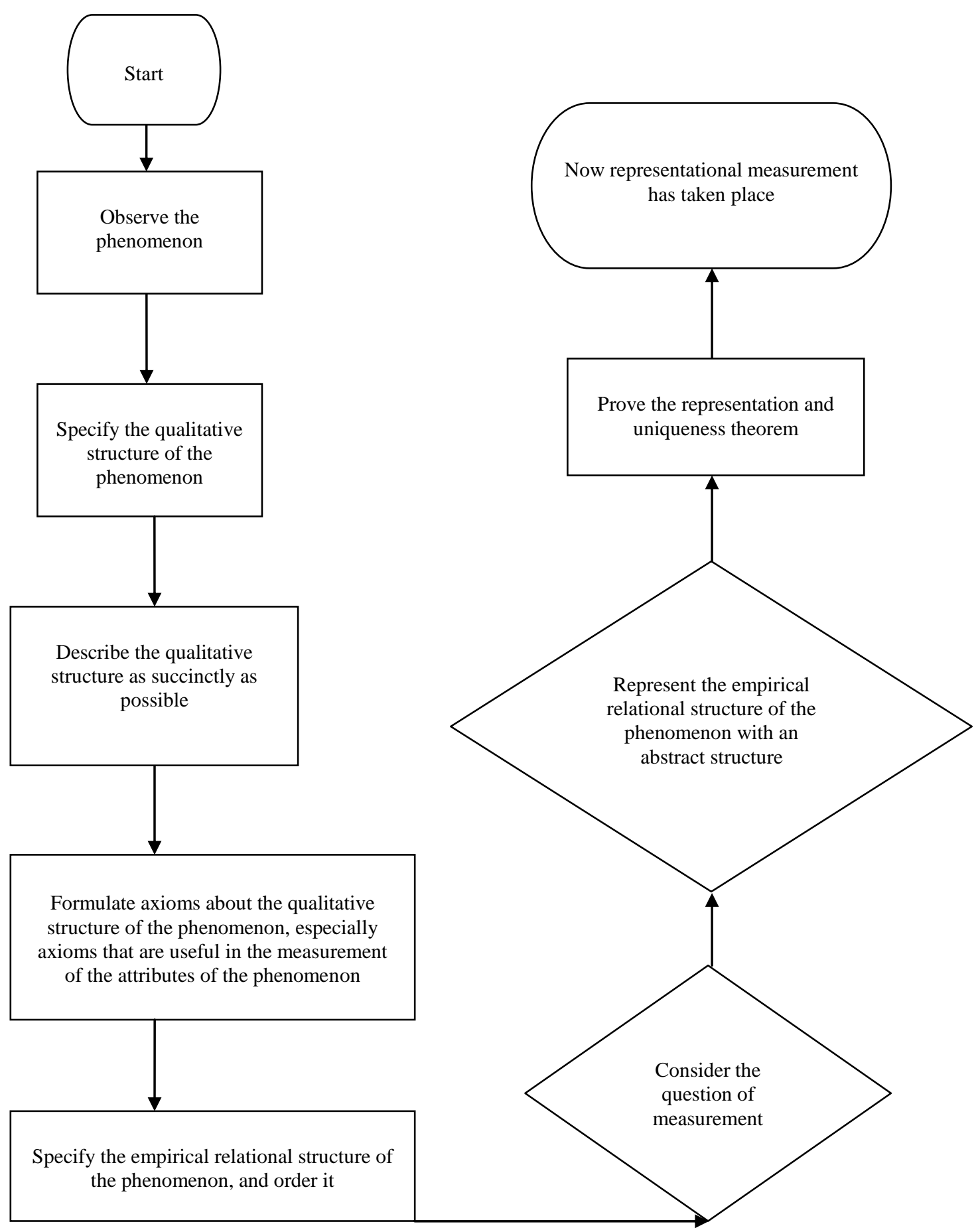

Figure 3.3.1 Flow Chart Depicting The Process Of Representational Measurement Source: Own Observation 
In essence, representational measurement is an attempt to understand the nature of empirical observations that can be recorded in some reasonably unique fashion in terms of familiar mathematical structures. According to Adams (1966), the representational theory of measurement is built on the basis that mathematical operations and relations are made to correspond to or represent empirical relations. From the flow chart it is clear that the question of measurement is only answered if it can be shown that the qualitative structure can be represented by an abstract structure. Real numbers are usually used for this purpose. The representation and uniqueness theorems are proved once a scale of measurement has been satisfied. In the accounting discipline (IASB, 2009) monetary units are considered to be measures of the value of the elements of financial statements. This means that a function that specifies the relationship between monetary units and value is a scale of measurement in accounting. In Section 3 it is noted that the relationship between monetary units and value is not known. This suggests that there are no scales of measurement in accounting. If accounting is to be considered a measurement discipline, there must be specified scales of measurement. These are the procedures that all the systems in the social sciences need to follow for measurement to take place. Currently, the requirements of representational measurement are not being fulfilled in the accounting discipline.

\subsection{The Misapplication Of The Concept Of Fundamental Measurement In Accounting}

The concept of fundamental measurement is easily applicable in the natural sciences. In the accounting discipline the concept is misapplied. According to Luce et al. (1990) measurement in the social sciences has been problematic to such an extent that social scientists have been strongly tempted to imitate the methods of the physical sciences. They point out that although this has been relatively successful in disciplines such as cognitive psychology, in a number of situations in the social sciences, however, physical measurements are used in a way that does not engage the full measurement structures that underlie them. This is the case in accounting. According to Ryan et al. (2002), the relationship between value and monetary units is not known. As a result, it is not clear whether monetary units as the representing structure clearly capture the intended properties of cost or value. Moreover, Stamp (1981), points out that cost or value is subjective. This means that value is a hypothetical quantity whose empirical relational structure is not known. Luce et al. (1990) point out that a physical measure that is thought to be an order-preserving index of some hypothetical underlying quantity, which itself has not received full measurement analysis, gives rise to indicants. If this is the case, it follows that the assignment of monetary units to the elements of the financial statements gives rise to indicants, not fundamental measurements. According to Stevens (1951), indicants are effects or correlates related to psychological dimensions by unknown laws. These indicants are commonly confused with measurements in accounting. For example, the IASB (2009) defines measurement as the assignment of monetary units to the cost or values of the elements of the financial statements. In this case, the relationship between value and the amount of monetary units paid for the value is not known. As a result, value is related to the quantity of monetary units assigned to represent it by unknown psychological laws.

According to Stevens (1951), measurement only occurs when the relationship between the indicant and the dimensions of the entity in question is known. Stevens (1951) also argues that the difference between an indicant and a measure is that the indicant is a presumed effect or correlate that bears an unknown (but usually monotonic) relation to some underlying phenomena, whereas a measure is a scaled value of the phenomenon itself. In accounting, it seems the word measurement is used to refer to both measurements and indicants. This is because monetary units are regarded as measures of value (see IASB, 2009) in the absence of a valid relationship between monetary units and value. Moreover, measurement magnitudes are historically and theoretically determined reflections of quantitative aspects of objectively existing entities and not merely the outcome of metricisation or measuring procedures (Decoene et al., 1995). If this is the case, it can be inferred from this that a measure of a phenomenon emerges from an explicit theory into which that phenomenon is incorporated. That is to say, all indicants are pre-theoretical and should not therefore be referred to as measurements. Moreover, the lack of success of accounting researchers in creating a theory of accounting measurement suggests that so-called accounting measurements are not measurements at all but indicants. According to Michell (1995) the aim of any theory of measurement is to account for the application of numerical mathematics in measurement. Given the absence of a theory of measurement in accounting, it may be argued that there is no accountability on how numbers are used in the discipline. That is, there is no theory (reason) that justifies the necessity of certain mathematical applications in accounting. Furthermore, the accounting discipline does not explain the reason why numerical mathematics is applied to economic phenomena; there are only specifications of where this is applied. For example, the ISAB 
(2009) does not explain why accounting measurement has to be the assignment of monetary units to represent the cost or value of the elements of the financial statements. In addition, it is also important to realise that any attempt by accountants to give any explanation would require additions to the accounting measurement theory.

However, it should be noted that there is nothing wrong with the use of indicants in a discipline. Luce et al. (1990) point out that the use of indicants for pre-theoretical variables may be a useful initial step towards the creation of such a theory for the measurement of the variable, but index creation for a variable must not be confused with the measurement of the variable. The confusion that is currently prevalent in the accounting discipline is that the amount of monetary units paid for the value of a commodity is considered to be a measure of the value of that commodity, but the amount of monetary units paid for the value of a commodity is merely an indicant. As a result the accounting discipline should drop the claim that it is capable of measuring value until such a time as it can prove that it is able to do so. Figure 3.4 below is a flow chart that compares indicants versus measurements. It highlights the differences in the process that creates indicants and the process that creates measurements.

The diagram illustrates the similarities between measurements and indicants. From the flow chart above, it is clear that measurement only occurs once the uniqueness and representation theorems can be proved. Luce and Narens (1994) point out that representational measurement occurs if and only if the representation and uniqueness theorems can be proved. It follows that proving these theorems is equivalent to proving a theory of measurement. According to Narens (2002), proving the uniqueness and representation theorems is equivalent to the establishment of a scale of measurement. For measurement to occur, a direct assessment of the phenomenon is required. But a direct assessment of the phenomena that are being measured is lacking in the accounting discipline. This is indicated by the fact that there is no known direct relationship between monetary units and the phenomena they are supposed to represent. Ryan et al. (2002:118) point out that there is no agreement relating the amount of monetary units paid to acquire a commodity and its value. This means that the amount of monetary units paid to acquire a commodity is an effect or correlate related to the psychological dimensions of value by unknown laws. It follows then that the amount of monetary units paid to acquire a commodity is not a scaled correlate of the underlying phenomenon of value. Consequently it can be concluded that, contrary to popular belief, value is not currently measurable in accounting.

\subsection{Measurement And Accounting Reality}

The principles of the representational theory of measurement can only be applied to something that is real. In Section 3.3 (Decoene et al., 1995), it was noted that magnitudes are historically and theoretically determined reflections of quantitative aspects of objectively existing entities, and not merely the outcome of metricisation or measuring procedures. This means that for the accounting discipline to be a measurement discipline, its measurement magnitudes must be descriptions of objectively existing accounting entities. In the accounting discipline, accounting realities are created by events. Events are about what has happened (Gouws and Van der Poll, 2004). Since measurement is possible only with empirical phenomena, it is clear that it is only the attributes of events that are measurable. According to Decoene et al. (1995), the defining feature of the representational theory of measurement is the belief that questions of measurement must be grounded in how reality is structured. In other words, the application of the representational theory of measurement depends entirely on the understanding of that part of the reality one is studying. Therefore, in order to measure the attributes of accounting events, an understanding of the qualitative structure of the accounting event is required. It would then be possible to identify the attributes of the reality one is studying. In addition, there is no way of posing the question of measurement of a variable prior to an understanding of the structure of that variable (Decoene et al., 1995). It is thus necessary to understand the phenomena that are being measured before measurement can take place. As a result, it is only the attributes of accounting events that are capable of being measured. 


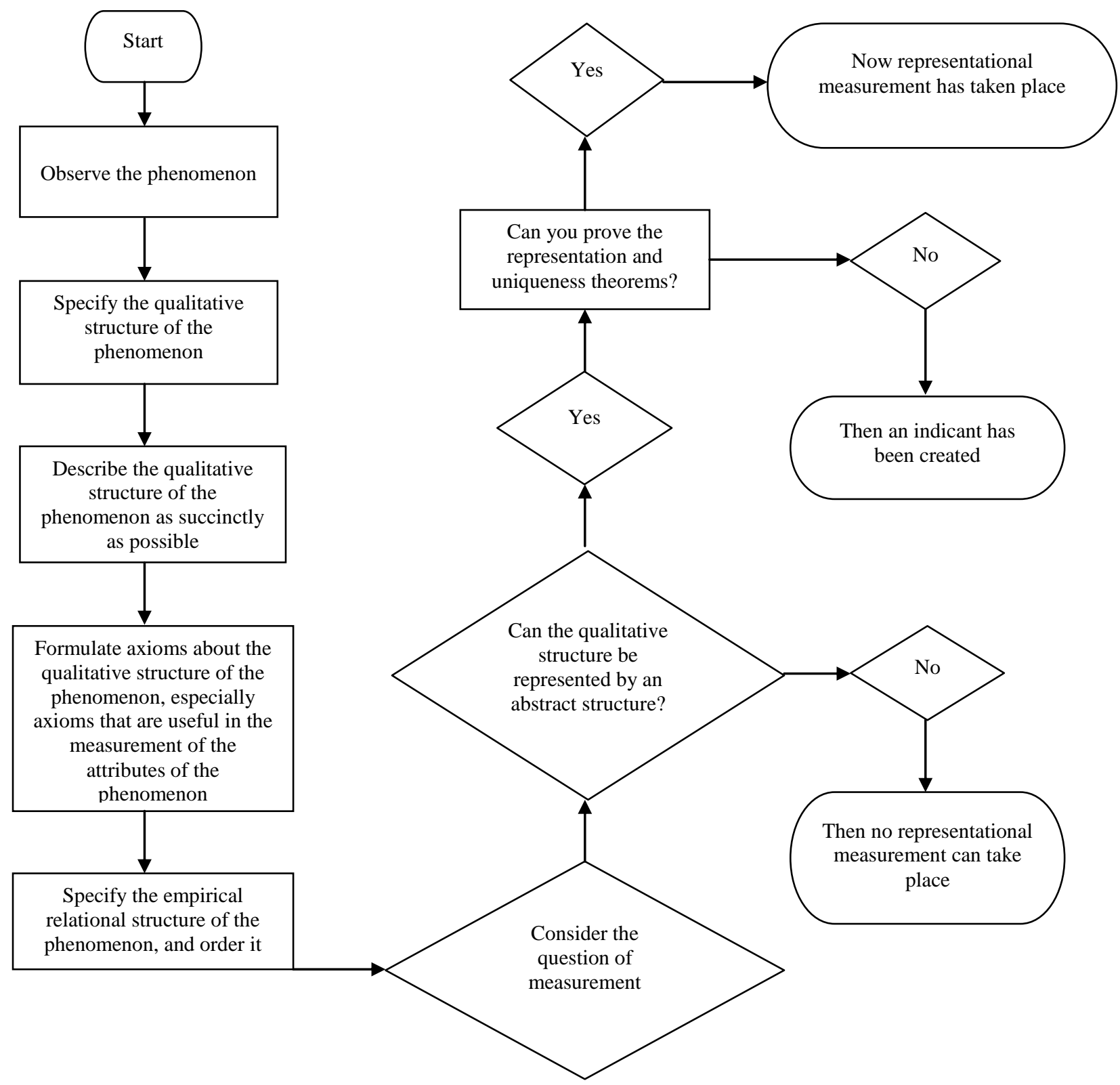

Figure 3.4 Measurements Versus Indicants

Source: Own Observation 


\subsection{Measurement And Simulated Reality In Accounting}

The accounting discipline plays loosely with the term "measure". It is conceivable that one may seek to quantify a property of some not yet existent phenomenon. The question is whether such quantifications can be described as measurements. The quantification of as yet non-existent phenomena is simulated reality. According to Gouws and Van der Poll (2004), simulated reality in the accounting discipline is regulated by assumptions, namely matching, accruals, prudence and going concern. Since assumptions are beliefs that something is true or that something will happen although there is no proof (Hornby, 2005), it follows that unknown psychological laws bind the properties of the phenomena that are subject to these beliefs. Consequently unknown laws also bind the amounts of monetary units assigned to the properties of simulated reality in the accounting discipline. The assignment of monetary units to the properties of simulated reality in accounting can thus only result in the production of indicants and not measures.

The general confusion between the identification of indicants and measures in the quantification of the attributes of simulated reality is a result of the current lack of success of the accounting discipline in identifying exactly what the numerosity of monetary units represents in accounting. Value is believed to be an important variable influencing the amount of monetary units paid to acquire a commodity, but the amount of monetary units indicates a ratio scale measure of monetary units and not of value. The ratio character of monetary unit measurement is based on the numerical representation of monetary unit intervals so that the value associated with the concatenation of adjacent intervals is the sum of values associated with those intervals. This is carried out in practice by counting the smallest denomination of the monetary units.

However, the viewpoint that the intervals of the units of value are represented by the intervals of monetary units has as far as is known nothing empirically to do with value. Authors such as Stamp (1981), Tinker (1985), McLean (2006) and Ryan et al. (2002) have noted that value is ambiguous and not an intrinsic property of anything. As a result, there is no general agreement among accountants about what value is and how it should be measured. If there is no reason for believing that the intervals of value are represented by the empirical structure of monetary units, then there is nothing empirical about value that limits which monotonic transformations of monetary units can be used as indices of value.

The operation of measuring, in the simplest of cases, entails the establishment, by observation, of correspondence between the magnitude of a property of an object and a particular point on a calibrated scale, which is designed to represent various magnitudes of that property (Chambers, 1997). This means that measurements must correspond closely to real world phenomena. That is to say, measurements must be true representations of the properties of the phenomena that they are measuring. Therefore measurements must exhibit the same properties as the phenomenon they are measuring. If they do not, they should not be classified as measurements.

Moreover, in accounting the source of simulated reality is future events. According to Gouws and Van der Poll (2004), the tool that was created to handle these "future events" is the so-called book entry. A book entry is a representation of something that has not happened and therefore cannot be observed. Thus quantifications of the attributes of phenomena represented by book entries do not correspond closely to real world phenomena and cannot be considered to be theoretical. They cannot help to explain real world phenomena and observations.

A theory of accounting measurement cannot therefore be developed from quantifications of the attributes of accounting simulated reality. It is also evident that the quantifications of the attributes of accounting simulated reality should not be aggregated as it is not known exactly what they represent. The quantifications of the attributes of accounting realities should not be added to each other or to the quantifications of the attributes of accounting simulated reality unless they satisfy the principle of homogeneity (Musvoto, 2008). According to the principle of homogeneity, such quantifications can only be added if the phenomena they are representing are not structurally different (Luce, 1996). The addition of monetary units representing simulated reality is common in the income statement and balance sheet (IASB, 2009). Thus the addition operation should not be used unless the homogeneity of the structures of the elements being added has been confirmed. 


\subsection{The Accounting Conceptual Framework As A Basis Of Accounting Measurement}

The common belief among accountants that the accounting conceptual framework contains the foundations of accounting measurement adds to the problems facing accounting today. The IASB (2009) conceptual framework for financial reporting is regarded as containing the foundations of measurement. Yet, as was established in Section 3.1.1, there are no foundations of accounting measurement in the accounting conceptual framework. This is also an indication that accountants are not familiar with the principles of the representational theory of measurement.

If this is the case, it follows that accounting should not be referred to as a measurement discipline. Furthermore, accountants need to be educated in the concept of representational measurement. Musvoto (2008) established that the bases of accounting measurement (historical cost, current cost, fair value, realisable value and present value) are not compatible with the principles of the representational theory of measurement. This indicates that accountants do not have an adequate understanding of the principles of the representational theory of measurement, with the result that they are not able to assess whether the accounting conceptual framework contains the foundations of accounting measurement.

\section{CREATING INDICANTS AND MEASUREMENTS IN THE ACCOUNTING DISCIPLINE}

In this section, part of phase 3 of the Mitroff et al. (1974) model is discussed. Part of the scientific model of the reality problem and part of the solution to the reality problem are covered in this section. The processes that the accounting discipline should follow in creating measurements and indicants are indicated. Currently the accounting discipline is creating indicants. Furthermore, as has been noted in Section 3.4, currently the accounting discipline refers to indicants as measurements. Figure 4.1 illustrates the processes of creating indicants. This is the scientific model of the problem situation. The figure also illustrates the processes that create measurements. This forms part of the solution to the reality problem. A full solution requires a proper definition of the measurement spaces of accounting phenomena and an empirical testing of the properties of the measurement space. It also involves the selection of abstract structures to represent the properties of the empirical relational structure of accounting phenomena. Empirical testing will also be required to ensure that the abstract structure exhibits the same properties as the empirical relational structure.

It should be noted that both measurements and indicants could be useful to a discipline. Stevens (1951) points out that indicants have the advantage of convenience, while measurements have the advantage of validity. A discipline may aspire to measure, but it is often forced to settle for indicants. From the analysis carried out in the previous chapters it is clear that this is indeed the case in the accounting discipline. According to Musvoto (2008) the qualitative characteristics of financial statements (namely comparability, reliability, relevance and understandability) indicate the need for the accounting discipline to be a measurement discipline. This discipline is currently considered to be a measurement discipline (e.g. IASB, 2009; Kirk, 2005; Vorster et al. , 2008; Wolk et al. 2001), when in fact it is not a measurement discipline, but rather a discipline that uses indicants. It is therefore necessary to outline the accounting processes that create an indicant and contrast them with those that can create measurements. Figure 4.1 below shows the processes that should be followed in accounting when creating a measurement and an indicant.

From the flow chart above, it is clear that there are two types of phenomena in accounting. One type can be observed while the other is based on simulated reality. Since, as Decoene et al. (1995) state, magnitudes are historically and theoretically determined reflections of quantitative aspects of objectively existing entities and not merely the outcome of metricisation or measuring procedures, it follows that with regard to observed reality in accounting such phenomena can be regarded as existing objectively. In order to measure their attributes a detailed theoretical analysis of the phenomena has to be carried out. The attribute that is of use and interest to measure should be identified, analysed and adequately understood. 


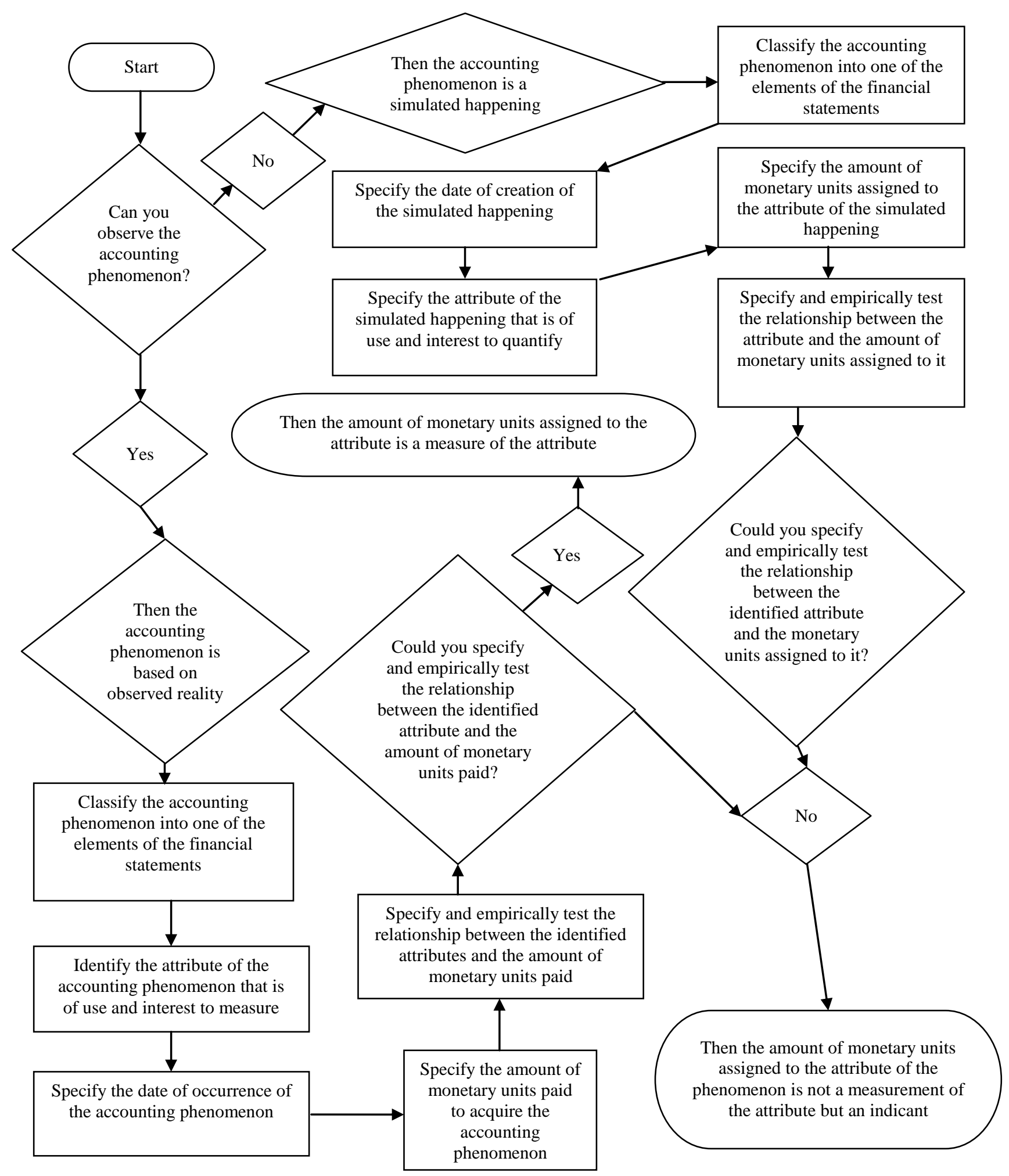

Figure 4.1 Steps To Creating Indicants And Measurements In Accounting Source: Own Observation 
In the accounting discipline an attribute that should be the subject of measurement is identified as cost or value. For instance, IASB (2009) points out that an item that meets the definition of an element should be recognised if it has a cost or value that can be measured with reliability. However, to date, the accounting discipline has not been able to clearly define cost or value. For example, Tinker (1985) points out that value and cost are both ambiguous concepts, and not intrinsic properties of an accounting entity. As a result, there is no general agreement among accountants on the meaning of cost or value. As outlined earlier (Ryan et al., 2002), there is no general agreement in the accounting discipline when relating the amount of monetary units paid for a commodity and its value. This means that there is no scale of assigning monetary units to the units of value in accounting. Therefore it follows that value is not measurable in accounting. According to Musvoto (2010), cost is an ambiguous concept. If this is the case, it follows then that cost cannot be defined precisely. Consequently, from the representational measurement perspective, cost is not measurable.

From the flow chart above it is clear that the relationship between value and the amount of monetary units used to represent value must be specified and the relationship must be empirically testable for measurement to occur. Furthermore, according to Orbach (1978:44), measurement theory requires that at least one empirical attribute be specified, but in the accounting discipline there is no such specification. As a result, what are referred to as measurements in accounting are merely indicants. With regard to simulated reality, as illustrated by the flow chart, no measurement is possible. This is because simulated realities do not have specified empirical attributes. The simulated realities are not empirical at all and consequently they cannot have empirical attributes. It can therefore be concluded that in accounting representational measurement is not possible with simulated reality.

\section{CONCLUSION}

In this study a comprehensive framework for approaching the measurement problem in accounting is proposed. It highlighted that the problem situation in accounting entails three interrelated shortcomings of the current application of the principles of representational measurement to accounting:

- $\quad$ The intuition that accounting phenomena can be represented numerically is pre-theoretical.

- The accounting discipline is oblivious to the idea that physical indices of accounting phenomena are not measurements.

- $\quad$ There is a lack of foundations for accounting measurement.

A representational form of measurement is proposed for the accounting discipline. Representational measurement is a theory that establishes measurement in the social sciences. Most of the quantifications in accounting fall under the concept of indicants. They thus fall short of the requirements of the representational theory of measurement. Moreover, in this study, the reality problem situation in accounting has been described; the conceptual model of the problem has been developed; and part of the scientific model of the reality problem and part of the solution to the reality problem has been discussed. Since accounting is considered to be a social science it would make sense if the accounting concept of measurement were compatible with the principles of the representational theory of measurement.

\section{AUTHOR INFORMATION}

S Wedzerai Musvoto, $\mathrm{PhD}$ is a senior lecturer in Financial Management and Accounting at the School of Accounting Sciences of the North-West University's Vaal Triangle Campus. He received his PhD from the University of Pretoria in 2008. Dr. Musvoto is also affiliated with the Association of Chartered Certified Accountants and the Chartered Institute of Management Accountants. His research interests include accounting measurement, risk management and the implications of modern principles of measurement on finance theory development. E-mail: 22838082@nwu.ac.za

\section{REFERENCES}

1. Adams, E.W. (1966). On the nature and purpose of measurement. Synthese, 16: 125-169.

2. Chambers R.J, (1997), Wanted: Foundations of Accounting Measurement. Abacus, 34 (1): 36-47. 
3. Decoene, S., Onghena, P. and Janssen, R. (1995). Representationalism under Attack. Journal of Mathematical Psychology, 39: 234-242.

4. Flanders, D., P. (1961) Accountancy, Systematized Learning, and Economics. The Accounting Review, 36: 564-576.

5. Gouws, D.G. and Van der Poll H.M. (2004), The integrity of information created through book entries. Meditari Accountancy research, 12 (1): 101-117.

6. Hornby. A.S. (2005), Oxford Advanced Learner's Dictionary of Current English, Oxford University Press, Oxford

7. International Accounting Standards Board (Iasb), 2009, International Financial Reporting Standards (IFRS) (2009): Including International Accounting Standards (IAS) and interpretations as at 1 July 2009.

8. Ijiri, Y. (1965). Axioms and Structures of Conventional Accounting Measurement, The Accounting Review: 36-53.

9. Ijiri, Y. (1967). The foundations of accounting measurement: a mathematical, economic and behavioural enquiry. Englewood Cliffs, N. J. Prentice-Hall

10. Ijiri, Y. (1975). Theory of Accounting Measurement, American Accounting Association

11. Kirk, R.J. (2005). International Financial Reporting Standards In Depth, Volume 1: Theory and practice, CIMA Publishing, An Imprint of Elsevier, Linacre House, Jordan Hill, Oxford OX2 8DP, 30 Corporate Drive, Burlington, MA 01803.

12. Luce, R, D., (1996) The ongoing Dialog between Empirical Science and Measurement Theory, Journal of Mathematical Psychology, 40: 78-98.

13. Luce, R. D., Krantz, D.H., Suppes, P. and Tversk, A. (1971), Foundations of Measurement, (Vol. 1) Additive and Polynomial representations, New York: Academic Press

14. Luce, R. D., Krantz, D.H., Suppes, P. and Tversk, A. (1990), Foundations of Measurement, (Vol. 3) Representations, axiomatization, and invariance, New York: Academic Press

15. Luce, R, D. and Narens, L. (1994), Fifteen Problems Concerning The Representational Theory of Measurement. Available, http:// www. Imbs.uci.edu / personnel / Luce / 1994/Luce \& Narens_Book \% 20 Chapter 1994.pdf, Accessed 2006/10/10.

16. McLean, R. (2006). New Concepts in Measuring Value, in (Ed), Einstein in the Boardroom, John Wiley \& Sons, Inc.

17. Michell, J. \& Ernst, C. (1996) The Axioms of Quantity and the Theory of Measurement, Journal of Mathematical Psychology 40, 235-252

18. Mitroff, I.I., Betz, F., Pondy, L.R. and Sagasti, F. (1974). On Managing Science in the systems age: two schemas for the study of science as a whole systems phenomenon. Interfaces, 4(3): 46-58.

19. Musvoto, S.W (2008) Applying the representational theory of measurement to accounting, PhD thesis, University of Pretoria, Pretoria, http://upetd.up.ac.za/thesis/available/etd-03282009-125051/

20. Musvoto S.W. (2010) Implications Of The Crisis Of Objectivity In Accounting Measurement On The Development Of Finance Theory, Tenth Annual IBER \& TLC Conference Proceedings 2010, Las Vegas, Nevada, USA,

21. Narens, L. (2002). A meaningful justification for the representational Theory of Measurement, Journal of Mathematical Psychology, 46: 746-768.

22. Orbach, K.N. (1978). Accounting as a Mathematical Measurement Theoretic Discipline, Unpublished PhD Thesis, Texas A\& M University

23. Ryan, B., Scapens, R.W., and Theobald, M. (2002), Research Method and Methodology in finance and Accounting, Second Edition, Mitcham, Surrey, International, Padstow, Cornwall.

24. Rivett, P. (1972). Principles of model building, London: John Wiley.

25. Stevens, S.S. (1951). Mathematics, Measurement and psychophysics, in (Ed), Handbook of Experimental psychology, New York: Wiley.

26. Stamp E. (1981) Why can Accounting not become a Science like Physics? Abacus, June: 13-27.

27. Tinker, T. (1985). Paper Prophets, A Social Critique of Accounting. New York: Praeger.

28. Staubus, G. J. (1985). An induced Theory of Accounting Measurement, The Accounting Review, January, 60(1): 53-75.

29. Vickrey, D. W. (1970). Is Accounting a Measurement Discipline? Accounting Review, 45 (4): $731-742$.

30. Walker, R.G. and Jones, S. (2003), Measurement: A way forward, Abacus: 39 (3): 356-374. 
31. Willet, R.J. (1987), An Axiomatic Theory of Accounting measurement. Accounting and Business Research: 155-171.

32. Willet, R.J. (1988) An Axiomatic Theory of Accounting Measurement - Part 2, Accounting and Business Research, 19(73): 79-91.

33. Wolk, H.I., Tearney, M.G. and Dodd, J.L. (2001) Accounting Theory: A conceptual and Institutional Approach. South Western College Publishing.

\section{NOTES}

